\title{
Crystal Structure of the Catalytic Domain of MMP-16/ MT3-MMP: Characterization of MT-MMP Specific Features
}

\author{
R. Lang ${ }^{1}$, M. Braun ${ }^{1}$, N. E. Sounni ${ }^{2}$, A. Noel $^{2}$, F. Frankenne ${ }^{2}$ J.-M. Foidart ${ }^{2}$, W. Bode ${ }^{1}$ and K. Maskos ${ }^{1}$ \\ ${ }^{1}$ Max-Planck-Institut für Biochemie, Abteilung Strukturforschung Am Klopferspitz 18a, D-82152 Martinsried-bei-munchen \\ ${ }^{2}$ Germany Laboratory of Tumor and Development Biology University of Liege, CHU Liege, Belgium
}

\begin{abstract}
Membrane-type matrix metalloproteinases (MT-MMPs) have attracted strong attention, because four of them can activate a key player in the tumor scenario, proMMP-2/progelatinase A. In addition to this indirect effect on the cellular environment, these MT-MMPs degrade extracellular matrix proteins, and their overproduction is associated with tumor growth. We have solved the structure of the catalytic domain (cd) of MT3-MMP/MMP-16 in complex with the hydroxamic acid inhibitor batimastat. CdMT3-MMP exhibits a classical MMP-fold with similarity to MT1-MMP Nevertheless, it also shows unique properties such as a modified MT-specific loop and a closed S1' specificity pocket, which might help to design specific inhibitors. Some MT-MMP-specific features, derived from the crystal structures of MT-1-MMP determined previously and MT3-MMP, and revealed in recent mutagenesis experiments, explain the impaired interaction of the MT-MMPs with TIMP-1. Docking experiments with proMMP-2 show some exposed loops including the MT-loop of cdMT3-MMP involved in the interaction with the proMMP-2 pro-domain in the activation encounter complex. This model might help to understand the experimentally proven importance of the MT-loop for the activation of proMMP-2.
\end{abstract}

Keywords: hydroxamate inhibitor; batimastat; matrix metalloprotease; membrane-type MMP

Abbreviations used: MMP, matrix metalloproteinase; MT, membrane-type.

\section{INTRODUCTION}

Matrix metalloproteinases (MMPs) are zinc-dependent endopeptidases, which are capable of collectively degrading all kinds of extracellular matrix proteins, but also can process a number of bioactive molecules. ${ }^{1}$ The MMPs play an important role in tissue remodeling associated with various physiological and pathological processes such as morphogenesis, angiogenesis, tissue repair, arthritis and tumor invasion. ${ }^{2-6}$ According to their cellular localization, the 23 human MMPs can be subdivided into 16 secreted and seven membrane bound MMPs. The latter MMPs include (i) the type-II transmembrane cysteine array MMP-23, ${ }^{7,8}$ (ii) the glycosyl phosphatidylinositol-attached MMPs 17 and 25/membrane-type MT-MMPs 4 and 6, ${ }^{9,10}$ and (iii) the type-I transmembrane MMPs 14, 15, 16, and 24/MT-MMPs 1, 2, 3, and 5. ${ }^{11}$ In addition, some secreted MMPs such as (pro)MMP-2 are recruited to and activated at the cell surface to make focal proteolysis. ${ }^{12}$ It has been proposed that this surface binding (e.g. via integrin interaction) might allow the fine control of ECM degradation near the cell surface of tumor cells. ${ }^{13}$ On the other hand, the location of membrane-type MMPs at the plasma membrane situates them in a position suitable to promote tumor invasion.

The MT-MMPs 1, 2, 3 and 5 play a dual role in cell surface proteolysis, in that they are able to cleave a variety of extracellular matrix components in vitro and to shed membrane-bound receptors, ${ }^{14}$ but are also capable of activating proMMP-2 (pro-gelatinase A). ${ }^{11}$ MT1-MMP seems to be the major activator of proMMP-2, mainly via presentation of proMMP-2 by a MT1-MMP-TIMP-2 "receptor". ${ }^{15-18}$ However, the catalytic domains or the fulllength molecules of the other MT-MMPs ${ }^{19-23}$ have also been shown in vitro or expressed in mammalian cells, respectively, to activate proMMP-2. Apparently, MT2-MMP is able to perform this activation in a TIMP-2independent manner. ${ }^{24}$ The proMMP-2 activation ability has been associated with a characteristic loop insertion (the MT-specific loop) ${ }^{25}$ between strands sII and sIII of the catalytic domain ${ }^{26}$ and, accordingly, the inefficiency in proMMP-2 activation of the classical MMPs and MT-MMPs $4^{27}$ and $6^{28,29}$ with the lack of this loop. The more severe phenotype exhibited by MT1-MMP knock-out mice compared with MMP-2 deficient mice ${ }^{30,31}$ indicates, however, that the MT-MMPs 1, 2, 3 and 5 play a much broader role than simply to activate proMMP-2. 
Figure 1. (a) Ribbon plot of cdMT3-MMP (yellow) displayed in stereo view (standard orientation). CdMT3-MMP, shown together with the bound batimastat inhibitor, is superimposed with the catalytic domains of MMP-1 (PDB accession code 1CGL), MMP-3 (1UEA), MMP-7 (1MMP), MMP-8 (1JAN), MMP-11 (1HV5), MMP-12 (1JK3), MMP-13 (456C), MMP-14 (1BQQ, pink), and MMP-2 (1QIB) and MMP-9 $(1 \mathrm{GKC})$ with the fibronectin type II repeats deleted. The catalytic and the structural zinc ion and the two bound calcium ions are displayed as pink and green spheres, respectively. The three His residues liganding the catalytic zinc and the characteristic Met264 are shown with all non-hydrogen atoms. The MT-loops of MT1-MMP and MT3-MMP significantly protrude away from the molecular surface compared with the sII-sIII bridges of the other MMPs. The Figure was made with BOBSCRIPT ${ }^{73}$ and Raster3D ${ }^{74}$. (b) and (c) Solid surface representation of the catalytic domain of MT3-MMP (b) and MT1-MMP (c) (1bqq). The molecules are shown in their front view in stereo (standard orientation), with a proMMP-2 derived Ser-Cys-Asn ${ }^{*}$ Leu-Phe-Val heptapeptide modelled into their active-site clefts. The coloring of the surface is according to the calculated negative and positive electrostatic potentials contoured from $-10 \mathrm{kT} / \mathrm{e}$ (red) to $+10 \mathrm{kT} / \mathrm{e}$ (blue). Noteworthy are the different shapes and charge distributions of the exposed MT-specific loops (left upper edge of the molecules). The Figure was made with Swiss-PDBViewer ${ }^{* 75}$ and POV-Ray/MegaPov ${ }^{\dagger}$. (d) Alignment of the MT3-MMP catalytic domain sequence with the catalytic domain sequences of other MMPs of known molecular structure, based on topological equivalence. Residues involved in binding of the catalytic and the structural zinc and of the two to three (in a few other MMPs) calcium ions are marked with Z1, Z2, C1, C2 and C3, and helices and strands of cdMT3-MMP are indicated by cylinders and arrows. The residue numbers refer to the sequence of the translated preproMT3-MMP molecule. ${ }^{22,38}$

a)

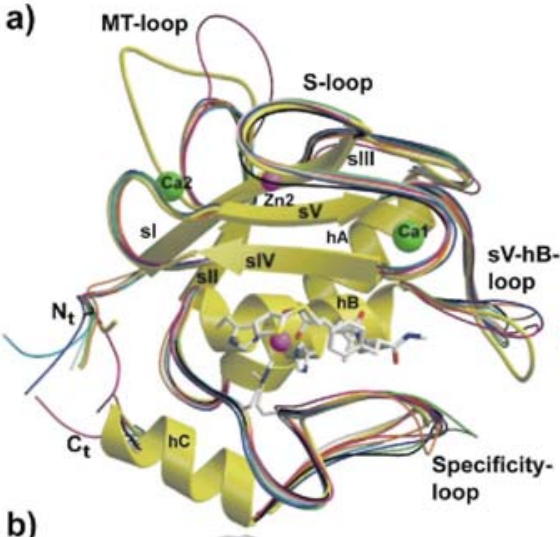

b)

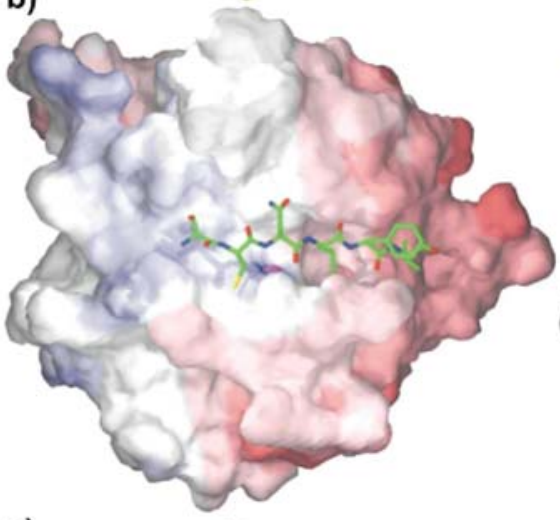

c)

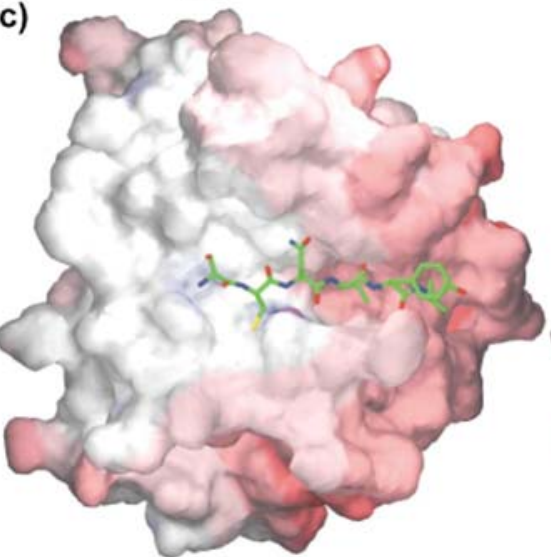

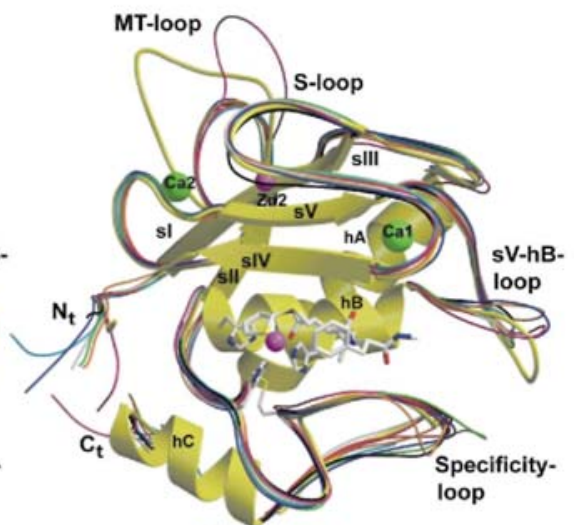
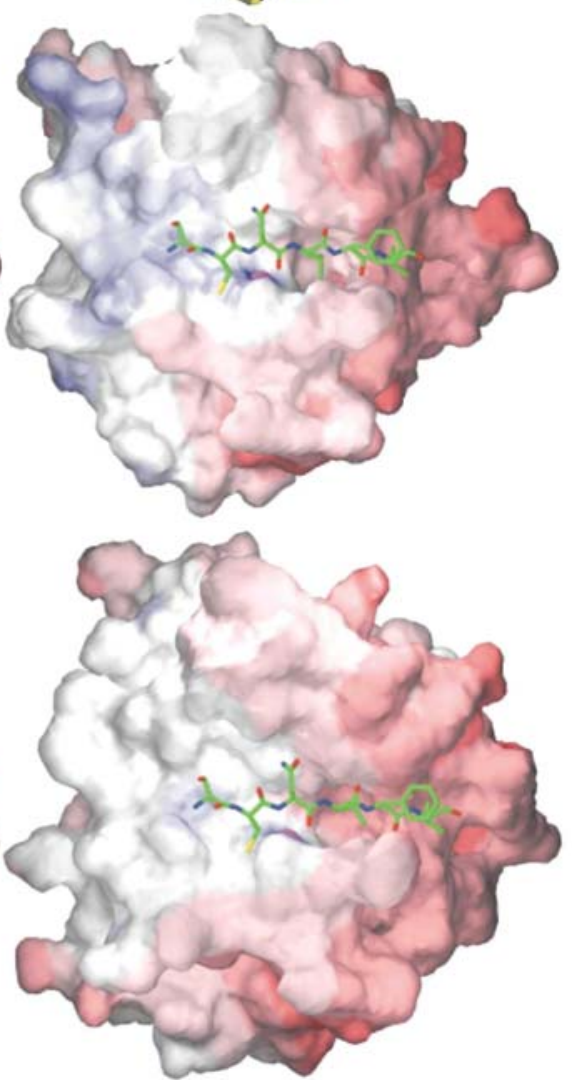

\footnotetext{
${ }^{*}$ http://www.expasy.org/spdbv/

${ }^{\dagger}$ POV-RAY (http://povray.org) and MegaPov (http:// nathan.kopp.com/patched.htm)
} 

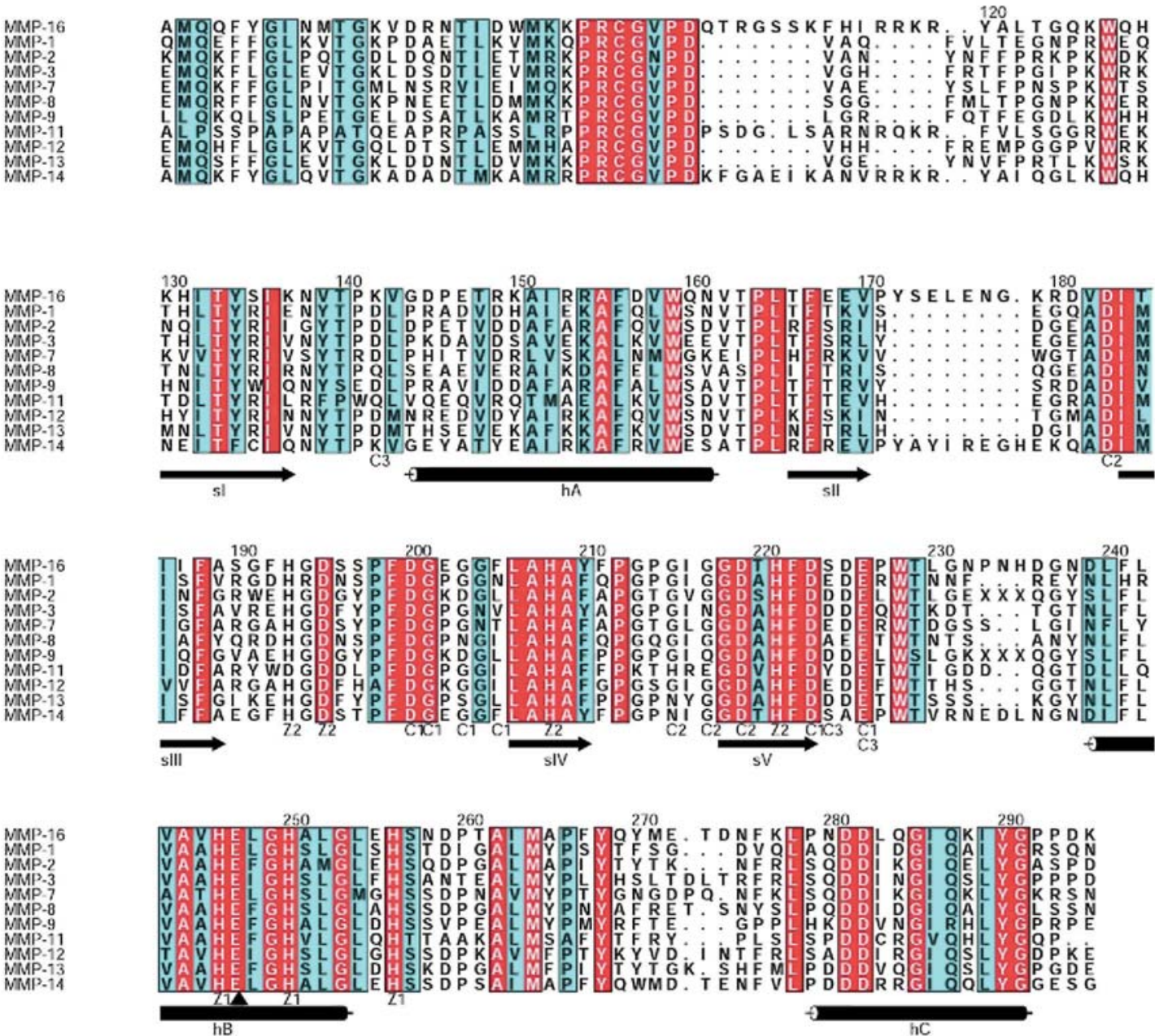

While MT-MMPs 1 and 2 are expressed in a variety of adult human tissues, expression of the MT-MMPs 3 and 5 seems to be restricted normally to the brain and the heart. ${ }^{21,32,33}$ MT3-MMP, like MT1-MMP, is highly expressed in cancerous tissues compared with normal tissues. It has been found in renal carcinoma, ${ }^{34}$ astrocytic tumors $^{33}$ and melanoma, ${ }^{32}$ while it was not detected in breast and thyroid carcinomas, which expressed MT1$\mathrm{MMP}^{35} \mathrm{MT} 3-\mathrm{MMP}$ has been shown to possess the potential to promote melanoma invasion by forming a complex with melanoma chondroitin sulfate proteoglycan, a cell surface proteoglycan expressed early in melanoma progression. ${ }^{36}$

MT3-MMP (originally described by Takino and co-workers ${ }^{22}$ ), similar to the related MT-MMPs, is translated as a multidomain 607-residue polypeptide chain, consisting of a short signal peptide, a prodomain linked via a multiple basic furin cleavage site ${ }^{37}$ with the catalytic domain, a long linker, a hemopexin-like domain, a transmembrane helix and a short cytoplasmic tail. Miyazaki and colleagues later published the slightly different cDNA sequence from human brain, which now seems to be generally accepted as the human MT3-MMP. ${ }^{38}$ Besides, a soluble human MT3-MMP species formed by alternative splicing has been described. ${ }^{39}$ MT3-MMP bears particularly strong sequence homology with MT5-MMPs. ${ }^{21,22,38}$ Like MT1-MMP, it is inhibited by TIMP-2 but not by TIMP-1. ${ }^{40}$ More efficiently than MT1-MMP does MT3-MMP digest type III collagen into typical one-and-three-quarter fragments, while it cleaves type I collagen only at the Gly4-Ile5 bond of the triple helical portion of the $\alpha 2(\mathrm{I})$ chain. $^{40}$

Previously, we have determined the structure of the MT1-MMP catalytic domain in complex with TIMP-2 and found some characteristic differences such as the MT-specific loop compared with the classical MMPs. ${ }^{25}$ Here we present the crystal structure of the related cdMT3-MMP in complex with the broad spectrum inhibitor batimastat. This structure hopefully will help in the rational design of more specific inhibitors, which might be useful for differentiating studies on the MT-MMPs. 


\section{RESULTS AND DISCUSSION}

\section{Overall structure}

The MT3-MMP crystals contain one copy of the complex formed between the catalytic domain of MT3-MMP (cdMT3-MMP) and the hydroxamic acid inhibitor batimastat (BB-94) per asymmetric unit. The first five residues of this construct (Met1-Tyr120 $0^{\mathrm{MT} 3}-$ Ala121 $1^{\mathrm{MT} 3}$-Leu122 $2^{\mathrm{MT} 3}-\mathrm{Thr} 123^{\mathrm{MT} 3}$; the superindex MT3 indicates MT3 residues numbered according to proMT3-MMP; in the following paragraphs, the superindices pro2, MT1, MT2, M1, M8, T1 and T2 will be used to refer to residues of proMMP-2, MT1-MMP, MT2-MMP, MMP-1, MMP-8, TIMP1 and TIMP-2, respectively) are not defined by electron density, although there is enough empty space in the crystal to accommodate it in an unconstrained manner. This indicates that the Tyr $120^{\mathrm{MT} 3} \alpha$-amino terminus of mature MT3-MMP (and thus, in general, the amino termini of the MT-MMPs) is inherently flexible and not involved in a surface-located salt bridge with Asp281 ${ }^{\mathrm{MT} 3}$ as observed in the collagenases, ${ }^{41}$ which is probably due to the two residues shorter amino terminus of activated MT-MMPs (Figure 1(d)) or the presence of the artificial methionine of our construct. Also the last 15 amino acid residues of this construct, which in the fulllength molecule would represent part of the 50-residue inter-domain linker, are not defined by electron density.

As in other MMPs, the MT3-MMP active-site cleft, which in the standard orientation (Figure 1) extends horizontally across the molecule and binds peptide substrates from left to right, separates the smaller "lower subdomain" from the larger "upper subdomain". The upper subdomain encompasses a five-stranded, highly twisted $\beta$-sheet, flanked by three surface loops on its convex side and by two long regular $\alpha$-helices on its concave side (Figure 1(a)). Four of the five $\beta$-strands are aligned in a parallel fashion, with only the cleft-sided "edge strand" sIV running in opposite direction. This latter strand is linked to the central strand sIII via the characteristic "S-shaped double loop" (S-loop), which is fixed via the "structural zinc" (Zn2, Figure 1(a)) and the first bound calcium ion (Ca1) to the underlying $\beta$-sheet. This S-loop extends into the cleft-sided "bulge", which continues into the antiparallel edge sIV, both together forming the alignment segment for binding peptidic substrates and inhibitors (see Figures 1 and 2). The end of the sII-sIII connecting segment, also called MT-loop due to its unique presence in MT-MMPs (see below), together with the sIV-sV loop sandwich the second calcium ion $(\mathrm{Ca} 2)$.

After strand $\mathrm{sV}$, the chain passes through the large open $\mathrm{sV}-\mathrm{hB}$ loop, another segment of high variability (Figure 1(a)) and a source of specificity ${ }^{42}$ before entering the long horizontally extending "active-site helix" $\mathrm{hB}$. This helix provides the first and the second His residue of the metzincin ${ }^{43}$ characteristic zinc-binding motif (His $246^{\text {MT3 }}$ and His $250^{\text {MT3 }}$, using the proenzyme numbering of MT3-MMP, together with the "catalytic" Glu2 $47^{\mathrm{MT} 3}$; see Figure 1(a) and (d)). Helix hB ends at Gly253 ${ }^{\mathrm{MT} 3}$, where the chain bends down, provides the third zinc ligand (His 256 ${ }^{\mathrm{MT} 3}$ ), passes the 1,4-tight "Met-turn" Ala262 ${ }^{\mathrm{MT} 3}$-IIe263 ${ }^{\mathrm{MT} 3}$-Met264 ${ }^{\mathrm{MT} 3}-\mathrm{Ala} 265^{\mathrm{MT} 3}{ }^{44}$ forms with Pro266 ${ }^{\text {MT3 }}$-Phe $267^{\text {MT3 }}-\mathrm{Tyr} 268^{\mathrm{MT} 3}$ the outer wall of the Sl'-pocket, and turns through the specificity loop back to helix $\mathrm{C}$.

The overall fold of the MT3-MMP catalytic domain is very similar to that of other MMPs of known structure. A total of $151 \alpha$-carbon atoms can (within $1.5 \AA$ Aistance, and with an r.m.s. deviation of $0.64 \AA$ ) be superimposed with equivalent $\alpha$-carbons of MT1-MMP, compared with, for example, 140/147 $\alpha$-carbons of MMP- $1^{45} / \mathrm{MMP}^{-44}$ (with rms deviations of $0.66 / 0.63$ Á), i.e. the overall fold is only marginally more similar within the MT-MMP subfamily Interesting deviations between MT1- and MT3-MMP are observed in the open sV-hB loop, the MT-loop and in the specificity loop (Figure 1(a)). According to the topology-based sequence alignment (Figure $1(\mathrm{~d})), 68 \%$ of the equivalent cdMT3-MMP residues (Tyr120 ${ }^{\mathrm{MT} 3}$-Gly291 ${ }^{\mathrm{MT} 3}$ ) are identical with those of MT1-MMP. Among all human MMPs, cdMT3-MMP should, with $80 \%$ identity, be most similar to cdMT5-MMP ${ }^{21}$.

\section{Active-site cleft and batimastat/substrate binding}

The active-site cleft of MT3-MMP is similar to that of MT1-MMP (Figure 2). The S3 pocket of MT3-MMP, formed by His $208^{\mathrm{MT} 3}$, Tyr210 ${ }^{\mathrm{MT} 3}$ and Ser197 ${ }^{\mathrm{MT} 3}$, differs only by a Ser/Thr replacement. Therefore, MT3-MMP might show a similar preference for Arg residues at P4 in the absence of P3-Pro residues. ${ }^{46}$ The hydrophobic S2 subsite is bordered by Glu255 $5^{\mathrm{MT} 3}$, so that its shallow groove could particularly well accommodate short hydrophobic side-chains (such as Cys, see below), but also Arg/Lys at P2; the corresponding Glu248 ${ }^{\mathrm{MT} 1}$ sidechain of MT1-MMP (see Figure 2) turns away from the S2 subsite, probably due to the presence of the amino terminus of the MT1-MMP catalytic domain co-crystallized with TIMP-2. ${ }^{25}$ The S1 cleft of MT3-MMP is, as that of MT1-MMP, bounded by the flat sides of the side-chains of His $208^{\text {MT3 }}$ (one of the ligands of the structural zinc) and Phe205 ${ }^{\mathrm{MT} 3}$ (Figure 2), distinguishing it from the S1 sites of most other MMPs. 
Figure 2. Stereo view toward the active site, (a) Protein residues and the batimastat inhibitor are shown as white (carbon atoms) and yellow (carbon atoms) sticks, respectively. Sulfur atoms are depicted in green, while zinc and calcium ions are represented by pink and blue spheres, respectively. The $2 F_{0}-F_{C}$ simulated annealing omit map of batimastat is contoured at $1 \sigma$. (b) and (c) The protein surfaces of MT3-MMP (b) and MT1-MMP (c) are shown as solid surfaces, colored according to negative (red) and positive (blue) electrostatic surface potential. The catalytic zinc ion is partially exposed (central pink sphere). The bound batimastat inhibitor of cdMT3-MMP is shown with atom colors (green carbon atoms), while the bound TIMP-2 is removed from the cdMT1-MMP/TIMP-2 complex. ${ }^{25}$ In contrast to the continuous S1' tube (to the right of the catalytic zinc, (c)) of MT1-MMP, the S1' specificity pocket of cdMT3-MMP is blocked. Figures were made with Swiss PDBViewer ${ }^{75}$ and PoV-Ray /MegaPov.

(a)

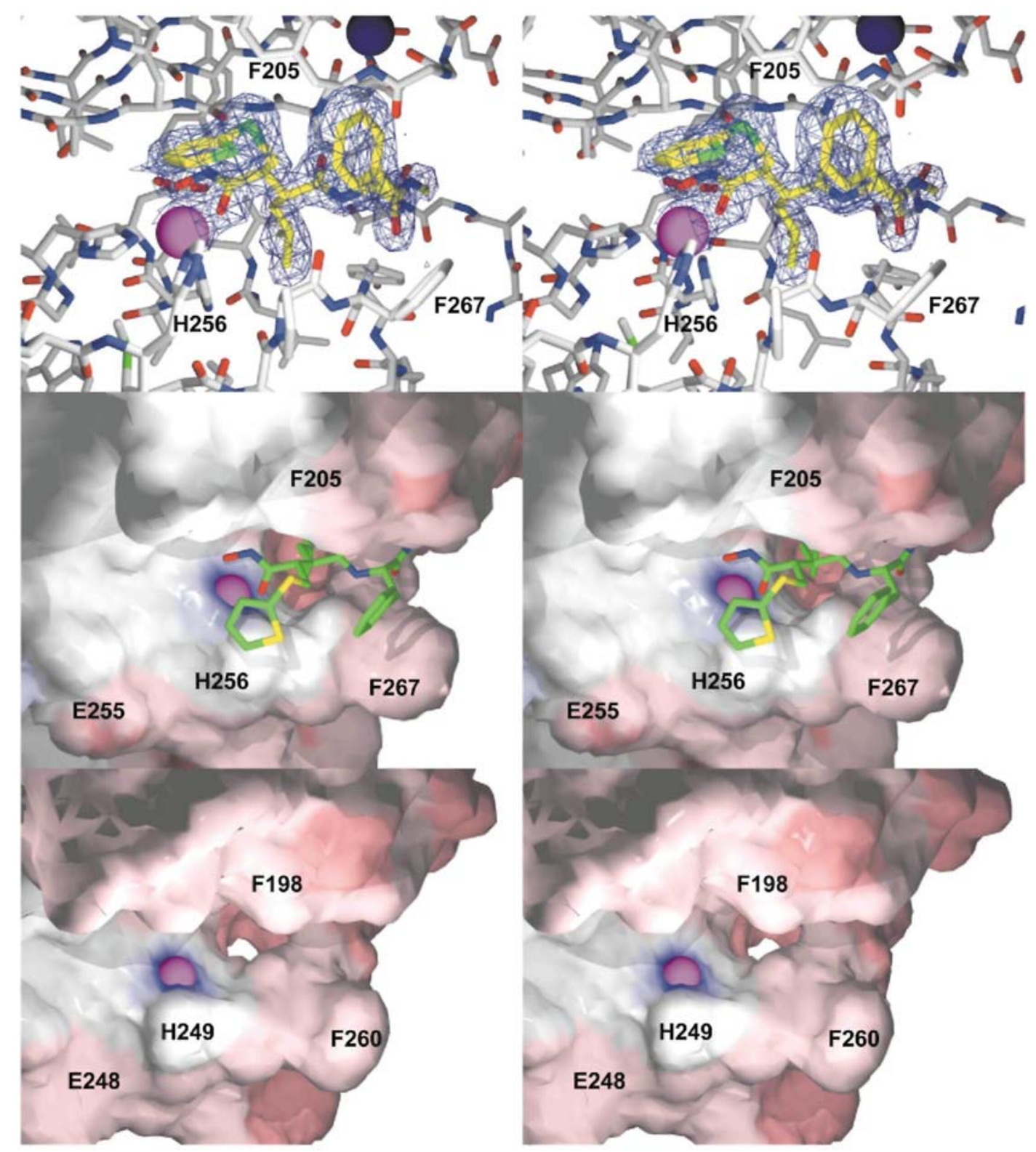

The entrance to the S1' subsite is mostly hydrophobic as in the other MMPs. In contrast to the MT1-MMP, however, the MT3-MMP S1'-subsite is not a continuous pore but a limited pocket, bounded at its bottom by the

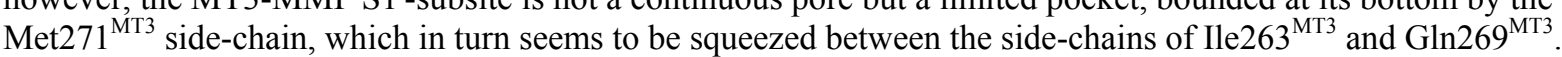
The equivalent Met264 ${ }^{\mathrm{MT1}}$ side-chain of MT1-MMP, packed between similar neighbors, is rotated out of the pocket and gives way to the S1' pore, possibly due to lack of a laterally stabilizing Tyr2 $270^{\mathrm{MT3}}-\mathrm{Asn} 234^{\mathrm{MT3}}$ sidechain stack as found in MT3-MMP This S1' difference is also reflected in main-chain deviations of the embracing specificity loop (Figure 1). We note that the equivalent Arg222 $2^{\mathrm{M} 8}$ side-chain of MMP- ${ }^{44}$ secludes the S1' pocket in a similar manner as observed in MT3-MMP However, a recent MMP-1/inhibitor structure shows that long side-chains in S1' are able to displace the occluding Arg2 $14^{\mathrm{M} 1}$ in MMP- $1 .{ }^{47}$ Such flexibility in pocket size may also be assumed for MT3-MMP. 
The S2' subsite is bordered by the protruding benzyl side-chain of Phe205 ${ }^{\mathrm{MT} 3}$ and the integrated benzyl group of Phe $267^{\mathrm{MT} 3}$, provided by the bulge-edge segment and by the S1' wall forming segment (see Figure 2(a) and (b)). The S2' groove of MT1-MMP, with identical residues, is very similar. With the exception of MT4-MMP, both Phe residues are conserved among the MT-MMPs, but are replaced by medium-sized and/or more polar residues in the classical MMPs. Thus, the inability of MT3-MMP to cleave, like MT1-MMP, collagen type I into threequarter and one-quarter fragments cannot be explained by significant structural differences in the active site cleft, but must rather reside in different exosite interactions, or result from a combination of multiple subtle contacts.

The bound batimastat inhibitor is well defined by appropriate electron density (Figure 2(a)). It coordinates the catalytic zinc ion in a bidentate manner via the hydroxyl (distance $2.24 \AA$ Á) and the carbonyl oxygen (distance $1.87 \AA$ ) of the hydroxamic group. Both oxygen atoms, together with the three ligating His nitrogen atoms (Zn distances between 2.02 and $2.16 \AA$ ) , make up a trigonal-bipyramidal coordination sphere around this zinc ion. The peptide-like backbone is bound similar to that observed in the corresponding batimastat complex with MMP- $8,{ }^{48}$ i.e. inserted between the bulge-edge strand and the wall-forming segment, under formation of five inter-main-chain hydrogen bonds (distances between 2.79 and $2.98 \AA \AA$ ). The thiophene ring, in $\alpha$-position to the hydroxamate moiety, is located above the catalytic zinc, but at a mean distance of $4.5 \AA$ Á, i.e. too far away for a favorable half-sandwich complex. The isopropyl group of batimastat, mimicking a P1' "Leu" side-chain, extends into the S1' pocket, still leaving space for a few more solvent molecules. The P2' phenyl ring forms both intra(with the thiophene ring) as well as intermolecular contacts (with Phe205 $5^{\mathrm{MT} 3}$ and Phe $267^{\mathrm{MT} 3}$ ), giving rise to a smooth surface spanning the primed region of the cleft.

The MT-specific loop and its possible involvement in proMMP-2 activation MT3-MMP shares with MT1-MMP (and probably with MT2- and MT5-MMP) the characteristic MT-loop that connects strands sII and sIII and forms a dominating protuberance on the molecular surface (see Figure 1). Here, 14 residues of the MT3-MMP chain between Glu168 ${ }^{\mathrm{MT3}}$ and Asp183 ${ }^{\mathrm{MT} 3}$ replace seven residues in the "classic" MMPs (Figure 1(d)) and the non-activating MT4-MMP, and ten residues in MT6-MMP The corresponding loop of MT5-MMP is of identical length, whereas the MT-loops of MT1- and MT2-MMP are one residue longer and (in the middle part) of different sequence. According to mutation/ deletion/kinetic experiments of Murphy and coworkers, ${ }^{26}$ the second half of the equivalent MT-loop of MT1-MMP is not particularly important, whereas the specifically structured $\mathrm{N}$-terminal part seems to be required for efficient activation of proMMP-2.

It is thus peculiar that just the N-terminal part of the MT3-MMP loop (Glu169 ${ }^{\text {MT3 }}-$ Val170 $0^{\text {MT3 }}$-Pro171 ${ }^{\text {MT3 }}$ -

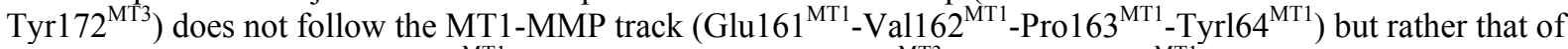
the classical MMPs, with Pro $163^{\mathrm{MT} 1}$ superimposing with Val170 $0^{\mathrm{MT} 3}$ and the Tyr164 ${ }^{\mathrm{MT1}}$ side-chain pointing in a different direction than the sequentially equivalent Tyr172 $2^{\mathrm{MT} 3}$, due to an extra bulge at Val162 $2^{\mathrm{MT} 1}$ and differing intramolecular packing. It should be mentioned that in both, the MT1-MMP-TIMP-2 structure ${ }^{25}$ as well as in this MT3-MMP-batimastat structure, the MT-loop protrudes into empty intermolecular gaps, relatively unconstrained by crystal contacts. The cdMT2-MMP from man has been shown to activate proMMP- $2,{ }^{24}$ and human and mouse MT2-MMPs expressed in COS cells were reported to be active. ${ }^{49}$ The same group in a later study found, however, that human MT2-MMP is defective, but that the cell-associated proMMP-2 activation function can be recovered by replacement of the human Glu181 ${ }^{\mathrm{MT} 2}-$ Val182 $2^{\mathrm{MT} 2}-\mathrm{Pro} 183^{\mathrm{MT} 2}-\mathrm{Tyr} 184^{\mathrm{MT} 2}-\mathrm{Glu} 185^{\mathrm{MT} 2}$ by the murine MT2-MMP Glu181 ${ }^{\text {MT2 }}$-Val182 $2^{\text {MT2}}$-Ser183 $3^{\text {MT2 }}$-Tyr $184^{\text {MT2 }}$-Asp $185^{\text {MT2 }}$ motif. ${ }^{50}$ According to Tyr ${ }^{\text {MT1 }} \rightarrow$ Ser mutation experiments of English and colleagues, ${ }^{26}$ the contained $\mathrm{Tyr}^{\mathrm{MT} 1}$ residue seems to play some role in the proMMP-2 activation, possibly acting as a molecular switch upon docking to proMMP-2. The different phenole placement in the MT1- and the MT3-MMP structures does not explain such a function, however, indicating that the mechanism of the MT-loop involvement in proMMP-2 activation is more complex.

The strong correlation of the presence of the MT-loop with the capability of activating proMMP-2, but also the mutation experiments mentioned above ${ }^{26}$ suggest a (direct or indirect) involvement of the MT-loop in proMMP2 activation. The MT1-MMP catalyzed proMMP-2 activation starts with a cleavage in the Glu63 $3^{\text {pro2 }}-S_{\text {Ser64 }}^{\text {pro2 }}-$ Cys6 $5^{\text {pro2 }}-$ Asn $66^{\text {pro2* }}$ Leu6 $7^{\text {pro2 }}-$ Phe $68^{\text {pro2 }}$ segment of proMMP-2, i.e. in the loop connecting helices 1 and 2 of the prodomain. ${ }^{51}$ The activation intermediate is then further processed and the final cleavage at Asn $109^{\text {pro2 }}$ Tyr $110^{\text {pro2 }}$ through another MMP-2 molecule yields active MMP-2. ${ }^{17,52,53}$ In both proMMP-2 structures ${ }^{51,54}$ the primary cleavage segment is in a position and conformation not accessible for an attacking MT1-MMP, and the residues flanking the primary cleavage site, in particular those C-terminal of it, exhibit enormously high temperature factors. This indicates that the cleavage segment is quite flexible and can adapt to an attacking MTMMP molecule. Modeling studies show that the primed side segment must partially unfold up to Lys $75^{\text {pro2 }}$ and adopt an MT-MMP-susceptible conformation ${ }^{55}$ (see model in Figure 1(b) and (c)), while the relatively rigid nonprimed side $\mathrm{Cys} 60^{\text {pro2 }}$-Cys $65^{\text {pro2 }}$ loop must slightly rearrange in order to become attackable by the approaching MT-MMP ${ }^{56}$ Manual docking experiments show that a refolded scissile proMMP-2 segment could insert into the 
active-site cleft of MT1/3-MMP in a productive manner, under simultaneous touch of helix 2 by the S-loop, insertion of the end of helix 1 below the S-loop, and contacts between the MMP-2 segment becoming the N terminus and the MT-loop (Figure 3(a)). In this way, the MT-loop could directly or indirectly stabilize the encounter complex facilitating proMMP-2 activation. Also other encounter complexes are conceivable, however, e.g. under association of both hemopexin-like domains. ${ }^{57}$ Interestingly, a hemopexin-like domain-dependent activation has been described for the MT2-MMP-dependent activation of proMMP- $2^{24}$ and the MT1-MMPdependent activation of proMMP-13. ${ }^{58}$

\section{TIMP-1 docking to MT-MMPs shows obstacles for interaction}

Previously we have shown for a cdMMP-3-TIMP- $1^{59}$ and for a cdMT1-MMP-TIMP-2 complex ${ }^{25}$ that the wedgeshaped TIMPs bind with their flexible edge consisting of six loops/segments into the entire active-site cleft of their cognate MMPs. The TIMPs mainly interact through their N-term-inal segment and the disulfide connected C-D loop, but make a number of contacts through the peripheral sA-sB loop and the two C-terminal loops. A superposition of both experimental complexes on the basis of the cdMMPs shows that the relative orientations of both cdMMPs and TIMPs differ considerably, what seems to be an inherent, characteristic difference between both TIMPs (Figure 3(a)). As a consequence, the C-terminal Cys $132^{\mathrm{T} 1}-\mathrm{Cys} 137^{\mathrm{T} 1}$ loop of TIMP-1 gets much closer to the sV-hB loop of the cognate MMP. In all MT-MMPs, the sV-hB loop is, however, longer for three residues (Figure 1(d)) and bulges out toward the approaching TIMP (see Figure 3(a)). Docking studies with TIMP-1 and MT3-MMP show that in particular Asn234 $4^{\mathrm{MT} 3}$ and His $235^{\mathrm{MT3}}$ would clash with Leu133 ${ }^{\mathrm{T} 1}$ and Ser $134^{\mathrm{T} 1}$. Favorable interactions here would require conformational adaptations, presumably on the cost of free energy of binding.

On the other hand, the favorable hydrophobic contacts between the TIMP-2 patch formed by Ile $157^{\mathrm{T} 2}$ and $\operatorname{Trp} 151^{\mathrm{T} 2}$ with Phe260 ${ }^{\mathrm{MT} 1}$ (Phe267 ${ }^{\mathrm{MT} 3}$ ) would not be possible with TIMP-1 (Figure 3(b)). In our modeled TIMP1-MT3-MMP complex, only the hydrophobic part of the Glu $156^{\mathrm{T} 1}$ side-chain would get into contact with Phe267 ${ }^{\text {MT3 }}$ (Phe is conserved in all human MT-MMPs except for MT4-MMP, where it is a Tyr). Furthermore, an MT1/3-MMP complex with TIMP-1 would lack the favorable interactions made by the extended sA-sB loop of TIMP-2, which in the MT1-MMP-TIMP-2 complex slots into the surface groove left by the MT-loop, the sidechains of Asp212 $2^{\mathrm{MT} 1}$ and Phe $250^{\mathrm{MT} 1}$, and the S-loop of MT1-MMP ${ }^{25}$ The importance of these interactions for the MT-MMP-TIMP-2 complex stability is shown by the 40-fold reduction in the apparent $K i$ value of the Tyr36 ${ }^{\text {T2 }}$ Gly sA-sB loop tip mutants (of N-TIMP-2) for association with MT1-MMP ${ }^{18}$ These interactions mediated through the sA-sB loop might also pull the "left" side of TIMP-2 (Figure 3(a)) towards the MT1-MMP molecule, thus preventing the approach of the "right" side, which in the modeled TIMP-1 complex shows clashes (see above). In summary, the crystal structures of MT1- and MT3-MMP are not in agreement with the favorable binding of TIMP-1, somewhat explaining the extremely low association reaction/affinity.

When we had completed this manuscript, we became aware of a new paper describing a triple mutant rendering TIMP-1 as active against MT1-MMP as other TIMPs. ${ }^{60}$ The critical replacement is that of Thr98 $8^{\mathrm{T} 1}$, which in our model faces a solvent-exposed cavity formed by the molecular MT1/3-MMP-TIMP-1 interface and just touches the side-chains of Pro266 ${ }^{\mathrm{MT} 3}$ and Phe $267^{\mathrm{MT} 3}$ (see Figure 3(b)), by Leu98 ${ }^{\mathrm{T} 1}$. In essence, the longer leucine sidechain in this position may interact more intimately with Pro $266^{\text {MT3 }}$ and may also touch His $256^{\text {MT3 }}$ and Phe $267^{\mathrm{MT} 3}$, thus forming a much better hydrophobic interaction with MT1/3-MMP Interestingly, Thr98 ${ }^{\mathrm{T} 1}$, which is located in the E-F loop of TIMP-1, is (because of the different loop conformation, but also due to different chain lengths) topologically equivalent to Leu $100^{\mathrm{T} 2}$ (Figure 3(b)). ${ }^{25}$ This makes the favorable effect of the Thr $\rightarrow$ Leu replacement somewhat conceivable, but not its extent. The multiple contacts of the inherently flexible TIMP loops make the assessment of replacement effects extremely difficult.

This mutant is remarkable in that it shows that small apparently insignificant changes in the TIMPs can shift the inhibitory answer from "no" to "yes". 
Figure 3. (a) Model of the encounter complex between cdMT3-MMP and proMMP-2. MT3-MMP is shown as orange ribbon with the MTloop in surface representation and the zinc and calcium ions in pink and green, respectively. The MT-MMP cleavage site of the prodomain (grey) of proMMP-2 (PDB code: 1CK7) was modeled into the active site of MT3-MMP (see the text). The catalytic domain, the fibronectin type-II repeats, the linker and the hemopexin-like domain are shown in green, purple, blue and yellow, respectively. The Figure was made with DS ViewerPro (Accelrys Inc.). (b) and (c) Stereo view of the experimental complex formed between cdMT1-MMP (blue) and TIMP-2 25 (gray) and a modeled (hypothetical) complex formed between cdMT3-MMP (yellow) and TIMP-1 (red). The position of TIMP-1 was obtained by superimposing the experimental cdMMP-3/TIMP-1 complex ${ }^{59}$ on the cdMT1-MMP/TIMP-2 complex on the basis of the MMPs. Finally, cdMMP-3 was deleted and cdMT3-MMP was superimposed on cdMTl-MMP (b) both complexes are shown with their front side, the active site clefts point toward the bottom. The sA-sB and sG-sH loops of TIMP have been labeled, and the sV-hB loops and the MT-loops of the MT-MMPs have been indicated. The Figure has been made with Swiss PDBViewert ${ }^{\dagger 75}$ (c) Stereo view of the close-up of the central TIMP binding site of the experimental cdMT1-MMP (blue)-TIMP2 (gray) complex and the modeled cdMT3-MMP (orange)-TIMP-1 (green) complex. The Figure was made with DS ViewerPro (Accelrys Inc.).

(a)
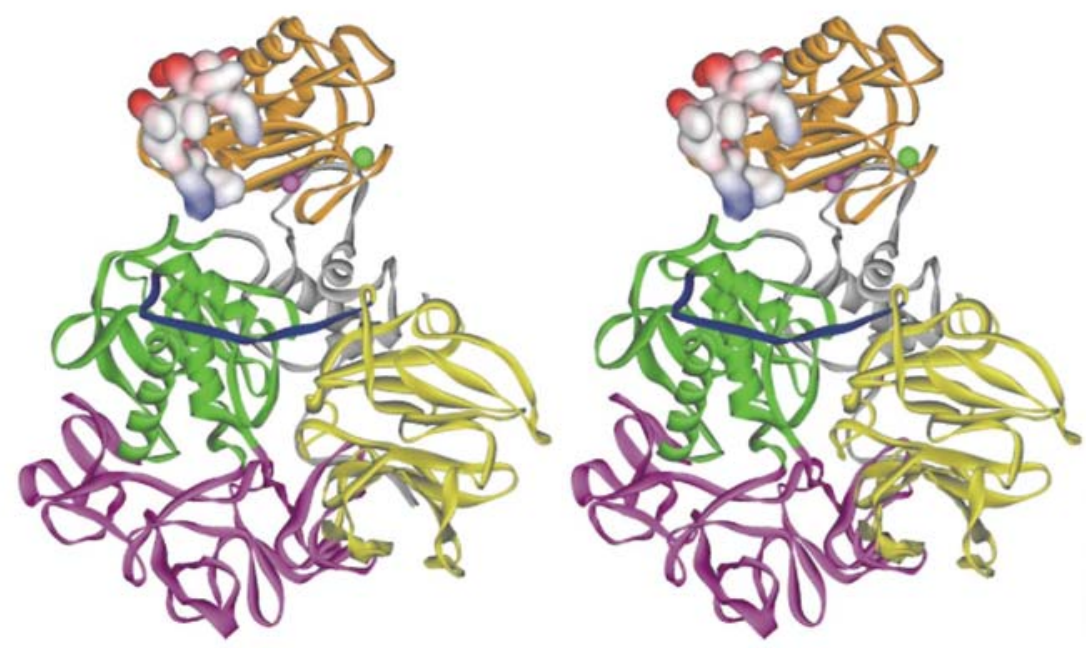

(b)
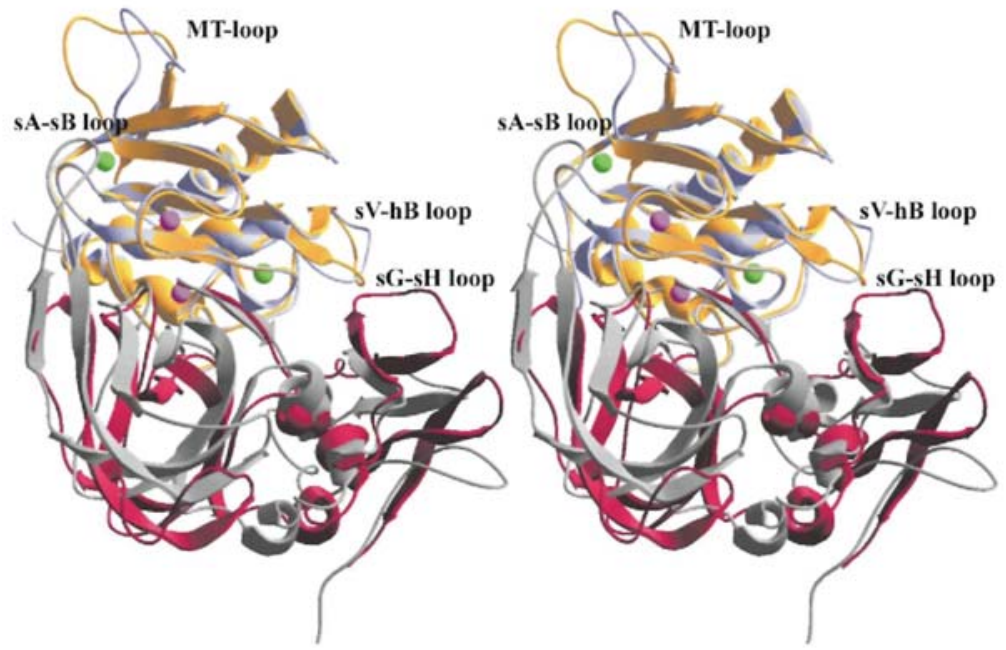

(c)

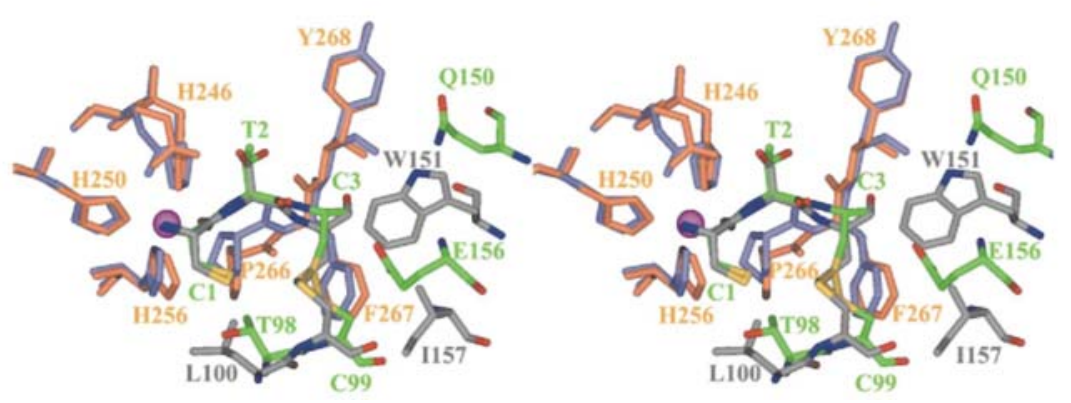




\section{MATERIALS AND METHODS}

\section{Cloning, expression, refolding and purification of cdMT3-MMP}

For the PCR amplification of the cDNA encoding cdMT3-MMP (from nucleotide 470 to nucleotide 1042), the MT3-MMP plasmid, kindly provided by H. Sato, was used as a template together with two synthetic nucleotide primers designed according to the known cDNA sequence (Accession number D50477). ${ }^{22}$ The sense primer 5'GGAATTCATATGTATGCATTGAC AGGACAGAA-3' and the antisense primer 5'-AA

CTGCAGCTAGCGGTGTGG GGGCACTGT-3' were designed to incorporate Nde I or Pst I sites (underlined) and an N-terminal methionine, respectively. The amplified PCR fragment was digested with these restriction enzymes and cloned into the pCTBR2 vector. ${ }^{61}$ The resulting plasmid was called pT7cdMT3.

BL21 (DE3) cells were transformed with the pT7cdMT3 plasmid and grown as described. ${ }^{62}$ The cdMT3 expression was induced by adding $0.5 \mathrm{mM}$ iso-propyl- $\beta$-D-galactopyranoside for three hours when the cell density reached an $\mathrm{A}_{600}$ of 0.6 . The cells were harvested by centrifugation and resuspended in lysis buffer (50 $\mathrm{mM}$ Tris- $\mathrm{HCl}$ ( $\mathrm{pH} 7.5), 100 \mathrm{KCl}, 0.1 \%$ Brij). The lysate was sonicated and the inclusion bodies were collected by centrifugation, and washed three times each with $50 \mathrm{mM}$ Tris- $\mathrm{HCl}(\mathrm{pH} 7.5), 2 \mathrm{M} \mathrm{NaCl}, 0.1 \%$ Brij, and with $50 \mathrm{mM}$ Tris- $\mathrm{HCl}(\mathrm{pH} 7.5)$.

Washed inclusion bodies were solubilized by stirring for two hours at $22^{\circ} \mathrm{C}$ in $50 \mathrm{mM}$ Tris- $\mathrm{HCl}(\mathrm{pH} 8.5), 8 \mathrm{M}$ urea, and $0.1 \% \beta$-mercaptoethanol. The denaturation mixture was dialyzed for four hours each at $4^{\circ} \mathrm{C}$ against a $50 \mathrm{mM}$ Tris- $\mathrm{HCl}$ ( $\mathrm{pH} 8.5$ ) buffer containing $100 \mathrm{mM} \mathrm{NaCl}, 10 \mathrm{mM} \mathrm{CaCl}, 100 \mu \mathrm{M} \mathrm{ZnCl}_{2}$, and urea at progressively decreasing concentrations in order to slowly eliminate urea. Additional dialyses were performed for 24 hours against Tris assay buffer $\left(50 \mathrm{mM}\right.$ Tris- $\left.\mathrm{HCl}(\mathrm{pH} 7.4), 100 \mathrm{mM} \mathrm{NaCl}, 5 \mathrm{mM} \mathrm{CaCl}, 1 \mu \mathrm{M} \mathrm{ZnCl}_{2}\right)$. The refolded cdMT3 (with residues Metl-Tyrl20 $0^{\mathrm{MT} 3}-\ldots-$-Pro30 $\left.7^{\mathrm{MT} 3}\right)^{38}$ was concentrated by ultra-filtration (3-kDa cutoff, YM3 membrane, Amicon), and the precipitate was removed by centrifugation after incubation overnight at $4{ }^{\circ} \mathrm{C}$. The supernatant was subjected to a HitrapQ anion-exchange column $(5 \mathrm{ml}$, Pharmacia) equilibrated with $50 \mathrm{mM}$ Tris- $\mathrm{HCl}(\mathrm{pH} 7.5)$ and $5 \mathrm{mM} \mathrm{CaCl}_{2}$, and eluted with a $\mathrm{NaCl}$ gradient $(0-500 \mathrm{mM})$ in $50 \mathrm{mM} \mathrm{Tris-HCl}$ $(\mathrm{pH} 7.5)$, and the peak fractions containing the homogenous cdMT3 were pooled.

\section{Crystallization, data collection, and structure refinement}

The human cdMT3-MMP-batimastat complex was crystallized using the sitting-drop vapor-diffusion technique. An aliquot of $1 \mu \mathrm{l}$ protein/inhibitor solution ( $50 \mathrm{mM}$ Tris- $\mathrm{HCl}(\mathrm{pH} 8.5), 100 \mathrm{mM} \mathrm{NaCl}, 5 \mathrm{mM} \mathrm{CaCl}{ }_{2}$, containing $10 \mathrm{mg} / \mathrm{ml}$ cdMT3-MMP and $0.5 \mathrm{mg} / \mathrm{ml}$ batimastat) was mixed with $1 \mu 1$ reservoir buffer $(100 \mathrm{mM}$ Tris- $\mathrm{HCl}(\mathrm{pH}$ 8.7), 1.1 M K/Na-tartrate) and concentrated against the reservoir at room temperature. Batimastat/ BB-94, a broad spectrum MMP-inhibitor with a $K i$ for MMP-1, -2 and -3 of about $1 \mathrm{nM},{ }^{63}$ was a generous gift from British Biotech. After a few days, brick-like crystals $(200 \mu \mathrm{m}$ X $200 \mu \mathrm{m}$ X $100 \mu \mathrm{m})$ formed belonging to the tetragonal space group $\mathrm{P}_{3} 22$ (Table 1). With one monomer of $21.3 \mathrm{kDa}$ per asymmetric unit, these crystals have a solvent content of $47 \%(\mathrm{v} / \mathrm{v})$.

After adding $20 \%(\mathrm{v} / \mathrm{v})$ glycerol to the mother liquor, a first data set to 2.2 A resolution was collected from a crystal cooled to $100 \mathrm{~K}$ in a nitrogen stream on a MAR-Research (Hamburg, Germany) 345 image plate detector by using monochromatized $\mathrm{CuK}_{\alpha}$ radiation produced by a conventional rotating anode. The data set was processed with the HKL package. ${ }^{64}$ The orientation and position of the human cdMT3-MMP-batimastat complex was determined by Patterson search techniques using the program $\mathrm{AMoRe}^{65}$ and the catalytic domain of human MT1-MMP (PDB accession code 1BQQ; residues: Пell4-Ser287) ${ }^{25}$ as a search model. A second dataset to 1.80 A resolution was collected with a flash-cryocooled crystal at a wavelength of $1.050 \mathrm{~A}$ at the beamline BW6 of the Deutsches Elektronen Synchrotron (DESY) in Hamburg, Germany, employing a Mar Research CCD detector. The structure of the human cdMT3/batimastat complex was refined with XPLOR ${ }^{66}$ using the Engh \& Huber parameters. ${ }^{67}$ The $\mathrm{Rf}_{\text {ree }}$ validation was based on a subset of $4.9 \%$ of the reflections omitted during the entire refinement procedure. In later stages of refinement, the maximum-likelihood algorithm implemented in the program $\mathrm{CNS}^{68}$ was used. Each round of refinement was followed by manual model rebuilding using the programs $\mathrm{O}^{69}$ and MAIN. ${ }^{70}$ 
Table 1. X-ray data and final refinement statistics

\begin{tabular}{|c|c|}
\hline \multicolumn{2}{|c|}{$\begin{array}{l}\text { Crystal cell constants: } a=51.21 \AA, b=51.21 \AA, c=149.37 \AA \text {, } \\
\alpha, \beta, \gamma=90^{\circ}\end{array}$} \\
\hline Space group: tetragonal & $\mathrm{P}_{3} 22$ \\
\hline Resolution $(\AA)$ & $16.60-1.80$ \\
\hline Mosaicity $\left({ }^{\circ}\right)$ & 0.4 \\
\hline Reflections measured & 119,029 \\
\hline Reflections unique & 18,455 \\
\hline$I / \sigma$, overall & 5.5 \\
\hline$I / \sigma(1.9-1.8 \AA ̊ ́)$ & 2.2 \\
\hline$R_{\text {merge }}(\%)^{\mathrm{a} /}$ overall & 8.3 \\
\hline$R_{\mathrm{merg} \varepsilon}(\%)^{\mathrm{a}},(1.9-1.8 \AA \AA)$ & 32.7 \\
\hline Completeness $(\%)$, overall & 96.7 \\
\hline Completeness $(\%),(1.9-1.8 \AA ̊)$ & 91.1 \\
\hline Number of non-hydrogen protein atoms & 1346 \\
\hline Number of inhibitor atoms & 32 \\
\hline Number of water molecules & 116 \\
\hline Reflections used for refinement & 17,555 \\
\hline$R$ value $^{\mathrm{b}}(\%)$ & 20.8 \\
\hline$R_{\text {merge }}{ }^{\mathrm{c}}(\%)$, from $4.9 \%$ of the data & 23.6 \\
\hline \multicolumn{2}{|l|}{ R.m.s. standard deviation } \\
\hline 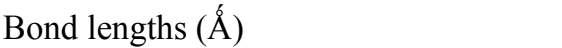 & 0.014 \\
\hline Bond angles (deg.) & 1.712 \\
\hline R.m.s. $B^{d}\left(\AA^{2}\right)$ & 3.907 \\
\hline Mean $B$ factor, protein main-chain $\left(\AA^{2}\right)$ & 28.7 \\
\hline Mean $B$ factor, protein side-chain $\left(\AA^{2}\right)$ & 31.1 \\
\hline Mean V factor, batimastat $\left(\AA^{2}\right)$ & 20.5 \\
\hline Mean $B$ factor, solvent $\left(\AA^{2}\right)$ & 37.3 \\
\hline \multicolumn{2}{|l|}{$\Phi, \Psi$ angle distribution ${ }^{\mathrm{e}}$} \\
\hline In core regions & $119(92.2 \%)$ \\
\hline In additionally allowed regions & $10(7.8 \%)$ \\
\hline \multicolumn{2}{|c|}{$\begin{array}{l}\text { a } R_{\text {merge }}=\left[\sum_{h} \sum_{i}|I(h, i)-\langle I(h)\rangle| / \sum_{h} \sum_{i} I(h, i)\right] \times 100 \text {. } \\
\text { b } R_{\text {value }}=\sum_{h k l}|| F_{\text {obs }}|-| F_{\text {calc }}|| / \sum_{h k l}\left|F_{\text {obs }}\right| \text {. } \\
\text { c } R_{\text {free }} \text { is the cross-validation } R \text { factor computed for the test set } \\
\text { of reflections }(4.9 \% \text { of total). } \\
\text { d R.m.s. } B \text { is the r.m.s. deviation of the } B \text {-factor of bonded } \\
\text { atoms. } \\
\text { e As defined by PROCHECK } 7^{72} \text { the percentage distribution is } \\
\text { given in parentheses. }\end{array}$} \\
\hline
\end{tabular}

The final refinement cycles with REFMAC ${ }^{71}$ led to a model with an R-value of 20.7. The final model consists of segment Gly124 ${ }^{\mathrm{MT} 3}$-...-Pro292 ${ }^{\mathrm{MT} 3}$ (cdMT3-MMP), the batimastat inhibitor, 115 water molecules, and two zinc and two calcium ions (Table 1). Except for discontinuous electron density in the MT-specific loop region Leu175 $5^{\text {MT3 }}$-Gly $178^{\text {MT3 }}$ and the sV-hB region His $235^{\text {MT3 }}-$ Asp $236^{\text {MT3 }}$, the cdMT3-MMP main-chain can be fully traced in continuous electron density. All main-chain angles of non-glycine residues fall into the most favored or allowed regions of the Ramachandran plot as defined by PROCHECK. ${ }^{72}$

\section{Protein Data Bank accession code}

The structure of the cdMT3-MMP/batimastat complex reported here has been deposited in the RCSB Protein Data Bank (PDB code: 1RM8). 


\section{Acknowledgements}

This project is funded by the European Commission as SPINE, contract no. QLG2-CT-2002-00988 under the Integrated programme "Quality of Life and Management of Living Resources". The financial support by the SFB469, the Fonds der Chemischen Industrie, the EU projects QLK3-CT-2002-02136 and QLG1-CT-200001131 and the Belgian Federation against Cancer is kindly acknowledged. We thank U. Rester, O. Einsle and C. Fernandez-Catalan for their help during data evaluation and Professor R. Huber for his continuous support of the project.

\section{References}

1. McQuibban, G. A., Gong, J. H., Tam, E. M., McCulloch, C. A., Clark-Lewis, I. \& Overall, C. M. (2000). Inflammation dampened by gelatinase A cleavage of monocyte chemoattractant protein-3. Science, 289, 1202-1206.

2. Noel, A., Gilles, C., Bajou, K., Devy L., Kebers, E, Lewalle, J. M. et al. (1997). Emerging roles for proteinases in cancer. Invasion Metastasis, 17, 221-239.

3. Nagase, H. \& Woessner, J. E, Jr (1999). Matrix metalloproteinases. J. Biol. Chem. 274, 21491-21494.

4. Stetler-Stevenson, W. G. (1999). Matrix metalloproteinases in angiogenesis: a moving target for therapeutic intervention. J. Clin. Invest. $103,1237-1241$

5. McCawley L. J. \& Matrisian, L. M. (2000). Matrix metalloproteinases: multifunctional contributors to tumor progression. Mol. Med. Today, 6, 149-156.

6. Sternlicht, M. D. \& Werb, Z. (2001). How matrix metalloproteinases regulate cell behavior. Annu. Rev. Cell. Dev. Biol. 17, 463-516.

7. Pei, D. (1999). CA-MMP: a matrix metalloproteinase with a novel cysteine array, but without the classic cysteine switch. FEBS Letters, $457,262-270$.

8. Velasco, G., Pendas, A. M., Fueyo, A., Rnauper, V., Murphy, G. \& Lopez-Otin, C. (1999). Cloning and characterization of human MMP23, a new matrix metalloproteinase predominantly expressed in reproductive tissues and lacking conserved domains in other family members. J. Biol. Chem. 274, 4570-4576.

9. Itoh, Y, Kajita, M., Kinoh, H., Mori, H., Okada, A. \& Seiki, M. (1999). Membrane type 4 matrix metalloproteinase (MT4-MMP, MMP17) is a glycosylphos-phatidylinositol-anchored proteinase. J. Biol. Chem. 274, 34260-34266.

10. Kojima, S., Itoh, Y., Matsumoto, S., Masuho, Y. \& Seiki, M. (2000). Membrane-type 6 matrix metalloproteinase (MT6-MMP, MMP-25) is the second glycosyl-phosphatidyl inositol (GPI)-anchored MMP. FEBS Letters, 480, 142-146.

11. Sato, H., Takino, T, Okada, Y, Cao, J., Shinagawa, A., Yamamoto, E. \& Seiki, M. (1994). A matrix metalloproteinase expressed on the surface of invasive tumour cells. Nature, 370, 61-65.

12. Overall, C. (2002). Molecular determinants of metalloproteinase substrate specificity: matrix metalloproteinase substrate binding domains, modules, and exosites. Mol. Biotechnol. 22, 51-86.

13. Deryugina, E. I., Bourdon, M. A., Jungwirth, K., Smith, J. W. \& Strongin, A. Y. (2000). Functional activation of integrin alpha V beta 3 in tumor cells expressing membrane-type 1 matrix metalloproteinase. Int. J. Cancer, 86, 15-23.

14. Kajita, M., Itoh, Y, Chiba, T., Mori, H., Okada, A., Kinoh, H. \& Seiki, M. (2001). Membrane-type 1 matrix metalloproteinase cleaves CD44 and promotes cell migration. J. Cell Biol. 153, 893-904.

15. Strongin, A. Y, Collier, I., Bannikov, G., Marmer, B. L., Grant, G. A. \& Goldberg, G. I. (1995). Mechanism of cell surface activation of $72-\mathrm{kDa}$ type IV collagenase. Isolation of the activated form of the membrane metalloprotease. J. Biol. Chem. 270, 5331-5338.

16. Kinoshita, T., Sato, H., Takino, T., Itoh, M., Akizawa, T. \& Seiki, M. (1996). Processing of a precursor of 72-kilodalton type IV collagenase/gelatinase A by a recombinant membrane-type 1 matrix metallo-proteinase. Cancer Res. 56, 2535-2538.

17. Will, H., Atkinson, S. J., Butler, G. S., Smith, B. \& Murphy, G. (1996). The soluble catalytic domain of membrane type 1 matrix metalloproteinase cleaves the propeptide of progelatinase A and initiates autoproteolytic activation. Regulation by TIMP-2 and TIMP-3. $J$. Biol. Chem. 271, 17119-17123.

18. Butler, G. S., Hutton, M., Wattam, B. A., Williamson, R. A., Knauper, V, Willenbrock, F. \& Murphy, G. (1999). The specificity of TIMP-2 for matrix metallo-proteinases can be modified by single amino acid mutations. J. Biol. Chem. 274, 20391-20396. 
19. Butler, G., Will, H., Atkinson, S. J. \& Murphy, G. (1997). Membrane-type-2 matrix metalloproteinase can initiate the processing of progelatinase A and is regulated by the tissue inhibitors of metalloproteinases. Eur. J. Biochem. 244, 653-657.

20. Kolkenbrock, H., Hecker-Kia, A., Orgel, D., Ulbrich, N. \& Will, H. (1997). Activation of progelatinase A and progelatinase A/TIMP-2 complex by membrane type 2-matrix metalloproteinase. Biol. Chem. 378, 71-76.

21. Llano, E., Pendas, A. M., Freije, J. P., Nakano, A., Knauper, V, Murphy, G. \& Lopez-Otin, C. (1999). Identification and characterization of human MT5-MMP, a new membrane-bound activator of progelatinase A overexpressed in brain tumors. Cancer Res. 59, $2570-2576$.

22. Takino, T., Sato, H., Shinagawa, A. \& Seiki, M. (1995). Identification of the second membrane-type matrix metalloproteinase (MTMMP-2) gene from a human placenta cDNA library. MT-MMPs form a unique membrane-type subclass in the MMP family. J. Biol. Chem. $270,23013-23020$

23. Pei, D. (1999). Identification and characterization of the fifth membrane-type matrix metalloproteinase MT5-MMP J. Biol. Chem. 274, $8925-8932$.

24. Morrison, C. J., Butler, G. S., Bigg, H. E, Roberts, C. R., Soloway, P. D. \& Overall, C. M. (2001). Cellular activation of MMP-2 (gelatinase A) by MT2-MMP occurs via a TIMP-2-independent pathway J. Biol. Chem. 276, 47402-474010.

25. Fernandez-Catalan, C, Bode, W., Huber, R., Turk, D., Calvete, J. J., Lichte, A. et al. (1998). Crystal structure of the complex formed by the membrane type 1-matrix metalloproteinase with the tissue inhibitor of metalloproteinases-2, the soluble progelatinase A receptor. EMBO J. 17, 5238-5248.

26. English, W. R., Holtz, B., Vogt, G., Knauper, V. \& Murphy, G. (2001). Characterization of the role of the MT-loop: an eight-amino acid insertion specific to progelatinase A (MMP2) activating membrane-type matrix metalloproteinases. J. Biol. Chem. 276, 42018-42026.

27. English, W. R., Puente, X. S., Freije, J. M., Knauper, V, Amour, A., Merryweather, A. et al. (2000). Membrane type 4 matrix metalloproteinase (MMP17) has tumor necrosis factor-alpha convertase activity but does not activate pro-MMP2. J. Biol. Chem. 275, 1404614055

28. Velasco, G., Cal, S., Merlos-Suarez, A., Ferrando, A. A., Alvarez, S., Nakano, A. et al. (2000). Human MT6-matrix metalloproteinase: identification, progelatinase A activation, and expression in brain tumors. Cancer Res. 60, 877-882.

29. Kojima, S., Itoh, Y., Matsumoto, S., Masuho, Y. \& Seiki, M. (2000). Membrane-type 6 matrix metalloproteinase (MT6-MMP, MMP-25) is the second glycosyl-phosphatidyl inositol (GPI)-anchored MMP. FEBS Letters, 480, 142-146.

30. Zhou, Z., Apte, S. S., Soininen, R., Cao, R., Baaklini, G. Y, Rauser, R. W. et al. (2000). Impaired endochondral ossification and angiogenesis in mice deficient in membrane-type matrix metalloproteinase I. Proc. Natl Acad. Sci. USA, 97, 4052-4057.

31. Holmbeck, K., Bianco, P., Caterina, J., Yamada, S., Kromer, M., Kuznetsov, S. A. et al. (1999). MT1-MMP-deficient mice develop dwarfism, osteopenia, arthritis, and connective tissue disease due to inadequate collagen turnover. Cell, 99, 81-92.

32. Yoshiyama, Y, Sato, H., Seiki, M., Shinagawa, A., Takahashi, M. \& Yamada, T. (1998). Expression of the membrane-type 3 matrix metalloproteinase (MT3-MMP) in human brain tissues. Acta Neuro-pathol. (Berl.), 96, 347-350.

33. Nakada, M., Nakamura, H., Ikeda, E., Fujimoto, N., Yamashita, J., Sato, H. et al. (1999). Expression and tissue localization of membrane-type 1, 2, and 3 matrix metalloproteinases in human astrocytic tumors. Am. J. Pathol. 154, 417-428.

34. Kitagawa, Y, Kunimi, K., Uchibayashi, T., Sato, H. \& Namiki, M. (1999). Expression of messenger RNAs for membrane-type 1, 2, and 3 matrix metalloproteinases in human renal cell carcinomas. J. Urol. 162, 905-909.

35. Ueno, H., Nakamura, H., Inoue, M., Imai, K., Noguchi, M., Sato, H. et al. (1997). Expression and tissue localization of membrane-types 1,2 , and 3 matrix metalloproteinases in human invasive breast carcinomas. Cancer Res. 57, 2055-2060.

36. Iida, J., Pei, D., Kang, T., Simpson, M. A., Herlyn, M., Furcht, L. T. \& McCarthy, J. B. (2001). Melanoma chondroitin sulfate proteoglycan regulates matrix metalloprotease-dependent human melanoma invasion into type I collagen. J. Biol. Chem. 276, 18786-18794.

37. Kang, T., Yi, J., Yang, W., Wang, X., Jiang, A. \& Pei, D. (2000). Functional characterization of MT3-MMP in transfected MDCK cells: progelatinase A activation and tubulogenesis in 3-D collagen lattice. FASEB J. 14, 2559-2568.

38. Shofuda, K., Yasumitsu, H., Nishihashi, A., Miki, K. \& Miyazaki, K. (1997). Expression of three membrane-type matrix metalloproteinases (MT-MMPs) in rat vascular smooth muscle cells and characterization of MT3-MMPs with and without transmembrane domain. J. Biol. Chem. 272, 9749-9754.

39. Matsumoto, S., Katoh, M., Saito, S., Watanabe, T. \& Masuho, Y. (1997). Identification of soluble type of membrane-type matrix metalloproteinase-3 formed by alternatively spliced mRNA. Biochim. Biophys. Acta, 1354, 159-170.

40. Shimada, T., Nakamura, H., Ohuchi, E., Fujii, Y, Murakami, Y, Sato, H. et al. (1999). Characterization of a truncated recombinant form of human membrane type 3 matrix metalloproteinase. Eur. J. Biochem. 262, 907-914. 
41. Reinemer, P., Grams, E, Huber, R., Kleine, T., Schnierer, S., Pieper, M. et al. (1994). Structural implications for the role of the N terminus in the, superactivation' of collagenases. A crystallographic study. FEBS Letters, 338, 227-233.

42. Chung, L., Shimakawa, K., Dinakarpandian, D., Grams, E, Firlds, G. B. \& Nagase, H. (2000). Identification of the (183)RWTNNFREY(191) region as a critical segment of matrix metalloprotease 1 for the expression of collagenolytic activity. J. Biol. Chem. 275, 29610-29617.

43. Bode, W., Gomis-Ruth, E X. \& Stocker, W. (1993). Astacins, serralysins, snake venom and matrix metalloproteinases exhibit identical zinc-binding environments (HEXXHXXGXXH and Met-turn) and topologies and should be grouped into a common family, the metzincins. FEBS Letters, 331, 134-140.

44. Bode, W., Reinemer, P., Huber, R., Kleine, T., Schnierer, S. \& Tschesche, H. (1994). The X-ray crystal structure of the catalytic domain of human neutrophil collagenase inhibited by a substrate analogue reveals the essentials for catalysis and specificity. EMBO J. 13, $1263-$ 1269.

45. Lovejoy, B., Cleasby, A., Hassell, A. M., Longley, K., Luther, M. A., Weigl, D. et al. (1994). Structure of the catalytic domain of fibroblast collagenase complexed with an inhibitor. Science, 263, 375-377.

46. Kridel, S. J., Sawai, H., Ratnikov, B. I., Chan, E. I., Li, W., Godzik, A., Strongin, A. Y. et al. (2002). A unique substrate binding mode discriminates membrane type-1 matrix metalloproteinase from other matrix metalloproteinases. J. Biol. Chem. 277, 23788-23793.

47. Lovejoy, B., Welch, A. R., Carr, S., Luong, C, Broka, C, Hendricks, R. T. et al. (1999). Crystal structures of MMP-1 and -13 reveal the structural basis for selectivity of collagenase inhibitors. Nat. Struct. Biol. 6, 217-221.

48. Grams, E, Crimmin, M., Hinnes, L., Huxley, P., Pieper, M., Tschesche, H. \& Bode, W. (1995). Structure determination and analysis of human neutrophil collagenase complexed with a hydroxamate inhibitor. Biochemistry, 34, 14012-14020.

49. Tanaka, M., Sato, H., Takino, T., Iwata, K., Inoue, M. \& Seiki, M. (1997). Isolation of a mouse MT2-MMP gene from a lung cDNA library and identification of its product. FEBS Letters, 402, 219-222.

50. Miyamori, H., Takino, T., Seiki, M. \& Sato, H. (2000). Human membrane type-2 matrix metalloproteinase is defective in cell-associated activation of progelati-nase A. Biochem. Biophys. Res. Commun. 267, 796-800.

51. Morgunova, E., Tuuttila, A., Bergmann, U., Isupov, M., Lindqvist, Y., Schneider, G. \& Tryggvason, K. (1999). Structure of human promatrix metallo-proteinase-2: activation mechanism revealed. Science, 284, 1667-1670.

52. Strongin, A. Y, Marmer, B. L., Grant, G. A. \& Goldberg, G. I. (1993). Plasma membrane-dependent activation of the 72-kDa type IV collagenase is prevented by complex formation with TIMP-2. J. Biol. Chem. 268, 14033-14039.

53. Atkinson, S. J., Crabbe, T., Cowell, S., Ward, R. V., Butler, M. J., Sato, H. et al. (1995). Intermolecular autolytic cleavage can contribute to the activation of progelatinase A by cell membranes. J. Biol. Chem. 270, 30479-30485.

54. Morgunova, E., Tuuttila, A., Bergmann, U. \& Tryggvason, K. (2002). Structural insights into the complex formation of latent matrix metalloproteinase 2 with tissue inhibitor of metalloproteinase 2. Proc. Natl Acad. Sci. USA, 99, 7414-7419.

55. Grams, E, Reinemer, P., Powers, J. C, Kleine, T., Pieper, M., Tschesche, H., Huber, R. \& Bode, W. (1995). X-ray structures of human neutrophil collagenase complexed with peptide hydroxamate and peptide thiol inhibitors. Implications for substrate binding and rational drug design. Eur. J. Biochem. 228, 830-841.

56. Bode, W. \& Maskos, K. (2003). Structural basis of the matrix metalloproteinases and their physiological inhibitors, the tissue inhibitors of metalloproteinases. Biol. Chem. 384, 863-872.

57. Lang, R. (2001). Röntgenstrukturanalyse der kataly-tischen Domänen von Makrophagen Elastase (MMP-12), MT3-MMP (MMP-16) und dem Komplex aus Kollagenase-3 (MMP-13) mit TIMP-2. Dissertation, Miinchen.

58. Knauper, V., Bailey, L., Worley, J. R., Soloway, P., Patterson, M. L. \& Murphy, G. (2002). Cellular activation of proMMP-13 by MT1MMP depends on the C-terminal domain of MMP-13. FEBS Letters, 532, 127-130.

59. Gomis-Ruth, F. X., Maskos, K., Betz, M., Bergner, A., Huber, R., Suzuki, K. et al. (1997). Mechanism of inhibition of the human matrix metalloproteinase stromelysin-1 by TIMP-1. Nature, 389, 77-81.

60. Lee, M. H., Rapti, M. \& Murphy, G. (2003). Unveiling the surface epitopes that render tissue inhibitor of metalloproteinase (TIMP)-1 inactive against membrane type 1-matrix metalloproteinase (MT1-MMP). J. Biol. Chem. 278, 40224-40230.

61. L'Hoir, C, Renard, A. \& Martial, J. A. (1990). Expression in Escherichia coli of two mutated genes encoding the cholera toxin B subunit. Gene, 89, 47-52.

62. Noel, A., Santavicca, M., Stall, I., L'Hoir, C, Staub, A., Murphy, G. et al. (1995). Identification of structural determinants controlling human and mouse stromelysin-3 proteolytic activities. J. Biol. Chem. 270, 22866-22872. 
Published in: Journal of Molecular Biology (2004), vol. 336, iss.1, pp. 213-225

Status: Postprint (Author's version)

63. Amour, A., Slocombe, P. M., Webster, A., Butler, M., Knight, C. G., Smith, B. J. et al. (1998). TNF-alpha converting enzyme (TACE) is inhibited by TIMP-3. FEBS Letters, 435, 39-44.

64. Otwinowski, Z. \& Minor, W. (1997). Processing of X-ray diffraction data collected in oscillations mode. Methods Enzymol. 276, 307326.

65. Navaza, J. (1994). AMoRe: an automated package for molecular replacement. Acta Crystallog. A50, 157-163.

66. Briinger, A. T. (1992). X-PLOR Version 3.1. A system for X-ray crystallography and NMR, Yale University Press, New Haven, CT.

67. Engh, R. A. \& Huber, R. (1991). Accurate bond and angle parameters for X-ray protein structure refinement. Acta Crystallog. sect. D, $4(1), 392-400$.

68. Brünger, A. T., Adams, P. D., Clore, G. M., Delano, W. L., Gros, P., Grosse-Kunstleve, R. W. et al. (1998). Crystallography and NMR systems (CNS): a new software system for macromolecular structure determination. Acta Crystallog. sect. D, 54, 905-921.

69. Jones, T. A., Zou, J. Y, Cowan, S. W. \& Kjelgaard, M. (1991). Improved methods for building protein models in electron density maps and the location of errors in these models. Acta Crystallog. A47, 110-119.

70. Turk, D. (1992). Weiterentwicklung eines Programms für Molekülgraphik und Elektronendichte-Manipu-lation und seine Anwendung auf verschiedene Protein-Strukturaufklärungen. Ph.D. thesis, Miinchen.

71. Murshudov, G. N., Lebedev, A., Vagin, A. A., Wilson, K. S. \& Dodson, E. J. (1999). Efficient anisotropic

refinement of macromolecular structures using FFT. Acta Crystallog. sect. D, 55, 247-255.

72. Laskowski, R. A., MacArthur, M. W., Moss, D. S. \& Thornton, J. M. (1993). PROCHECK: a program to check the stereochemical quality of protein structures. J. Appl. Crystallog. 26, 283-291.

73. Esnouf, R. M. (1997). An extensively modified version of MolScript that includes greatly enhanced coloring capabilities. J. Mol. Graph. Model. 15, 132-134.

74. Merritt, E. A. \& Murphy, M. E. P. (1994). Raster3D version 2.0. A program for photorealistic molecular graphics. Acta Crystallog. sect. $D, 50,869-873$

75. Guex, N. \& Peitsch, M. C. (1997). SWISS-MODEL and the Swiss-PdbViewer: an environment for comparative protein modeling. Electrophoresis, 18, 2714-2723. 